\title{
The Influence of Rice Husk on the Physical Properties of Portland Pozzoland Cement at the Cement Industry Scale
}

\author{
Agus Maryoto*, Gathot Heri Sudibyo \\ Department of Civil Engineering, Engineering Faculty, Jenderal Soedirman University, Indonesia
}

\begin{abstract}
This study aims to determine the effect of rice husk as a source of substitute fuel on the manufacture of cement at the industry scale. The parameters tested include the physical properties of the cement consisting of the Blain fineness test, false set, cement setting time, and mortar compressive strength at 3,7, and 28 days. The average values for the results of these tests on cement produced using rice husks as a substitute fuel were $380 \mathrm{~m}^{2} / \mathrm{kg}, 81 \%, 132$ minutes, 253 minutes, and 225,298 , and $379 \mathrm{~kg} / \mathrm{cm}^{2}$, respectively. Based on the test results, we have shown that rice husk ash has a good effect on the characteristics of cement type I which still meet the standards of SNI-20492015.
\end{abstract}

\section{Background}

Rice husk is a waste obtained from the process of rice production and is widely produced by countries that consume rice as a staple food. These countries include those located in Southeast Asia such as Indonesia, Malaysia, Thailand, Vietnam, and Myanmar. Japan, Korea, and China also produce rice as the staple food. As a waste, rice husk can be used as renewable fuel. In addition, rice production can be done three times a year, which is an advantage for the use of rice husk as renewable fuel. It is currently used on a small scale as fuel for the production of bricks and tile.

Indonesia is one of the countries whose inhabitants use rice as the main foodstuff. Central Java is one of the provinces in Indonesia where research is conducted, resulting in rice husk production of about 2.825 million tons per year. Low prices, a high caloric value, and renewable properties are all advantages of this fuel for its use in industrial cement production. The caloric value of rice husk is $2790 \mathrm{cal} / \mathrm{g}$ [1].

Some researchers have used raw rice husk for bricks [2], to make light concrete [3], and to investigate the chemical content of rice husk ash $[4,5]$ which mostly consists of $\mathrm{SiO}_{2}$ (about 90\%). The remaining chemicals are $\mathrm{Fe}_{2} \mathrm{O}_{3}, \mathrm{Al}_{2} \mathrm{O}_{3}$, and $\mathrm{CaO}$, which account for about 8 $9 \%$. This very large silica content of course has a very good effect on concrete. Laboratory-scale studies have been Srinivasreddy et al. [6] and Sisman et al. [7] to investigate the effect of rice husk ash on the workability, consistency, and setting time. Concrete that uses rice husk ash to replace some cement has better workability. Workability is characterized by an increased value of concrete slump. In addition, the utilization of rice husk ash in cement paste can reduce the setting time; increasing the amount of rice husk in cement results in longer initial and final setting times of the concrete [8].

Many reinforced concrete structures are located in corrosive areas such as coastal regions. Infiltration of chloride and sulfate ions will cause corrosion of concrete reinforcement. Chloride and sulfate ions infiltrate together with water absorbed by the concrete. Another advantage of the use of rice husk ash in concrete is that it can reduce water absorption so that corrosion by chloride and sulfate [9] can be minimized. In addition, rice husk utilization in concrete can improve its tensile and flexural strength [10]. Used in combination with fiber and superplasticizer, rice husk can improve the mechanical properties of concrete [11-14]. Even the fineness of rice husk ash also increases the durability of concrete [15].

The inclusion of rice husk ash in cement can improve the properties of concrete at the laboratory scale. Unfortunately, the use of rice husk as a fuel in the process of cement production on an industrial scale has not been well studied. This study aims to determine the effect of rice husk usage as a substitute fuel in the cement industry on the physical properties of Portland Pozzoland Cement.

\footnotetext{
* Corresponding author: agus_maryoto1971@yahoo.co.id
} 


\section{Method}

\subsection{Specimens}

This study was conducted on an industrial scale. The use of rice husk as an alternative fuel in cement production in the industry was observed for 12 days. The amount of rice husk used per hour is shown in Table 1.

The physical properties of the cement tested include the fineness, false set, initial and final setting time, and the compressive strength of mortar at an age of 3, 7, and 28 days based on the SNI (Indonesia National Standard) 2049-2015 [16] standard. The total number of specimens tested is shown in Table 2.

Table 1. Rice husk usage in cement industry.

\begin{tabular}{|c|c|}
\hline The sampling day & Rice husk usage (ton/hr) \\
\hline 1 & 7.97 \\
\hline 2 & 7.64 \\
\hline 3 & 6.88 \\
\hline 4 & 6.72 \\
\hline 5 & 5.18 \\
\hline 6 & 5.25 \\
\hline 7 & 6.84 \\
\hline 8 & 6.66 \\
\hline 9 & 7.01 \\
\hline 10 & 6.92 \\
\hline 11 & 4.80 \\
\hline 12 & 7.91 \\
\hline
\end{tabular}

Table 2. Number of specimens tested

\begin{tabular}{|c|l|c|}
\hline No. & \multicolumn{1}{|c|}{ Test } & $\begin{array}{c}\text { Number of } \\
\text { specimens }\end{array}$ \\
\hline 1 & $\begin{array}{l}\text { Fineness using Blaine } \\
\text { apparatus }\end{array}$ & 12 \\
\hline 2 & False set & 36 \\
\hline 3 & Initial setting time & 12 \\
\hline 4 & Final setting time & 12 \\
\hline 5 & $\begin{array}{l}\text { Compressive strength of } \\
\text { mortar 3-days old }\end{array}$ & 12 \\
\hline 6 & $\begin{array}{l}\text { Compressive strength of } \\
\text { mortar 7-days old }\end{array}$ & $\begin{array}{l}\text { Compressive strength of } \\
\text { mortar 28-days old }\end{array}$ \\
\hline 7
\end{tabular}

\subsection{Fineness of cement}

The test using a Blaine apparatus is aimed at determining the fineness of the cement expressed as its specific surface area, calculated as the total surface area in $\mathrm{cm}^{2} / \mathrm{g}$ or $\mathrm{m}^{2} / \mathrm{kg}$. The Blaine apparatus is essentially comprised of a device which sucks some amount of air through a Portland cement bed prepared with a certain porosity. This porosity is a function of the particle size and determines the rate of air flow through its base. The procedure is described below.

The Blaine apparatus is connected to a power source. The switch on the Blain apparatus located behind the panel is turned on. The "enter" button is pressed to start the testing process. The arrow keys on the panel are pressed according to the type of cement tested, then the "enter" button is pressed. The cement sample is weighed according to the weight shown on the monitor screen. Test tubes are prepared with a little Vaseline at the bottom of the tube. Filters of brass and filter paper are added, fully sealed onto the tube, with the filter paper positioned above the brass filter. The cement sample is then inserted into the tube. The tube is covered with a single sheet of filter paper, and the cement sample is compacted inside the tube by pressing the plunger to the maximum compression, after which the plunger is removed from the tube. The tube is then mounted in the Blaine tool. At the time of mounting the tube, the tube is slightly rotated so that the Vaseline is spread evenly which functions as a seal. The "enter" button is pressed so that the cement fineness analysis can take place. The fineness test results will appear on the screen when the analysis process ends, and the results of the cement fineness value are recorded. The "enter" button is then pressed to end the testing process. The Blain apparatus can be seen in Figure 1 .

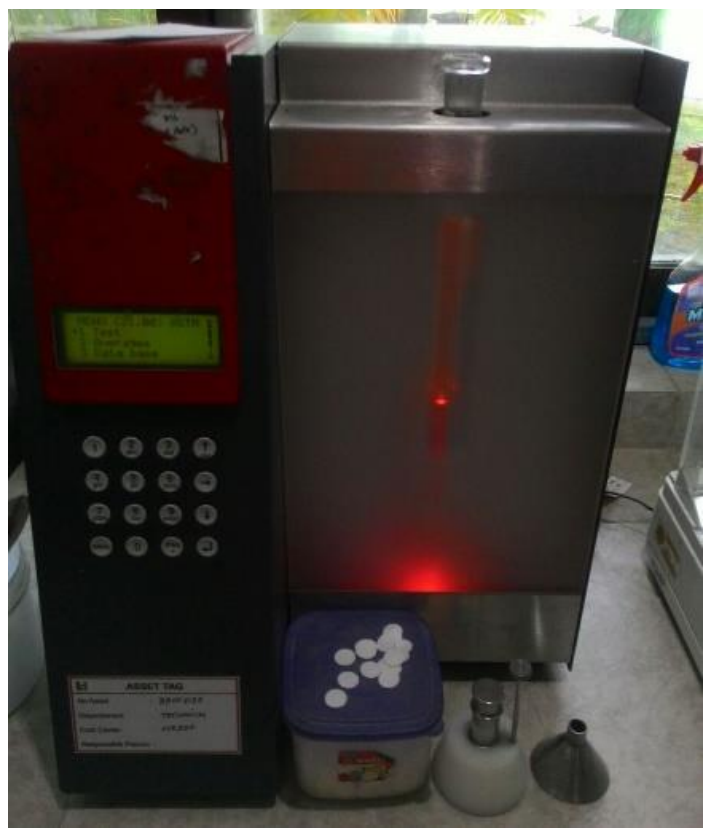

Fig. 1. Blaine apparatus. 


\subsection{False set}

False set is the development of an early stiffening in the Portland cement, mortar, or concrete without the evolution of much heat. This stiffness can be removed, and the plasticity is recovered by remixing without adding water. The false set testing process begins by mixing the cement with water for 4 minutes. The cement paste is then cast in the vicat ring. After 20 seconds of mixing time, the penetration test is carried out with a 10 $\mathrm{mm}$ vicat needle tool for 30 seconds. This penetration depth is the initial penetration. A second penetration test is performed on the paste 5 minutes after mixing. The depth of this test is called the final penetration. False set can then be calculated with the following equation:

$$
\text { False set }=\frac{\text { Final Penetration }}{\text { Initial Penetration }} \times 100 \%
$$

\subsection{Initial and final setting time}

A cement paste is made by mixing around $300 \mathrm{~g}$ of cement with some water. The weight of water used is obtained from the normal consistency test of the cement. The cement and water are mixed for 3 minutes. The cement paste is then put into the vicat ring, and the test specimen is placed in a humid room for 30 minutes to continue the binding process. Penetration testing is done every 15 minutes. The vicat tool used is $1 \mathrm{~mm}$ in diameter and is released in order to penetrate the cement paste for 30 seconds. The distance between the penetration points on the cement paste is at least $10 \mathrm{~mm}$, and the difference between the penetration point distance and the nearest wall is at least $5 \mathrm{~mm}$. The initial setting time is reached when the penetration depth is equal to 25 $\mathrm{mm}$, calculated from the start of mixing water with the cement until the time penetration reaches $25 \mathrm{~mm}$ deep. The final setting time is reached when the needle does not penetrate into the cement paste. The initial and final setting time processes are shown in Figures 2 and 3.

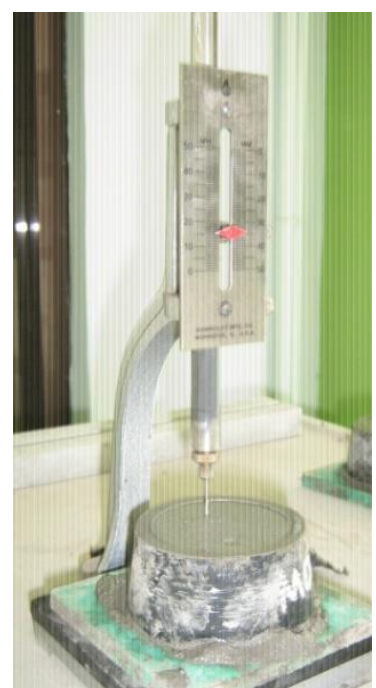

Fig. 2. Initial setting time.



Fig. 3. Final setting time.

\subsection{Compressive strength of mortar}

A mixture of mortar is made from 1 part cement, 2.75 parts sand by weight, and some water. The water/cement ratio used in the mortar is 0.485 . The mortar mixture of consists of $740 \mathrm{~g}$ of cement, $2035 \mathrm{~g}$ of sand, and $359 \mathrm{~mL}$ of water. Water is put into the bowl first, then the cement is added to the bowl. The mortar is then run in a speed mixer at about $140 \mathrm{rpm}$ for 30 seconds. The sand is added slowly within the 30 seconds while the mixer keeps spinning at $140 \mathrm{rpm}$. The mixer is then stopped so that its speed can be changed, and the mortar is left for 1.5 minutes in the bowl. Mortar adhered to the bowl wall is cleaned for the first 15 seconds of the interval, and then the bowl is closed. Then mixing is done again for 1 minute at a speed of about $285 \mathrm{rpm}$. The mortar cube specimen is nine pieces.

Casting of specimens can then be done. Mortar is put into a $50 \times 50 \times 50 \mathrm{~mm}$ cube mold to a thickness of 25 $\mathrm{mm}$. The mortar is then compacted in as many as $4 \times 8$ rounds. Compaction rounds 1 and 3 are in opposite directions to compaction rounds 2 and 4 . The left-hand side of Figure 4 represents the compaction of rounds 1 and 3, while the right describes the compaction in rounds 2 and 4. After compaction of the first layer is complete, the mold is refilled with mortar and it is compacted as in the first layer. After casting of the mortar is complete, the specimen is placed in a humid chamber for 20-72 hours. The specimen is removed from the mold after 24 hours and then treated by soaking in water with a temperature of $23 \pm 2{ }^{\circ} \mathrm{C}$. The specimen is removed from the water pond when the compressive test time has arrived. This test is conducted to determine the mortar compressive strength at the pre-determined age. The specimen surface is cleaned of the water content. The compressive strength of the mortar can then be obtained by testing using a compression machine as shown in Figure 5. The amount of compressive strength is calculated by Equation 2 .
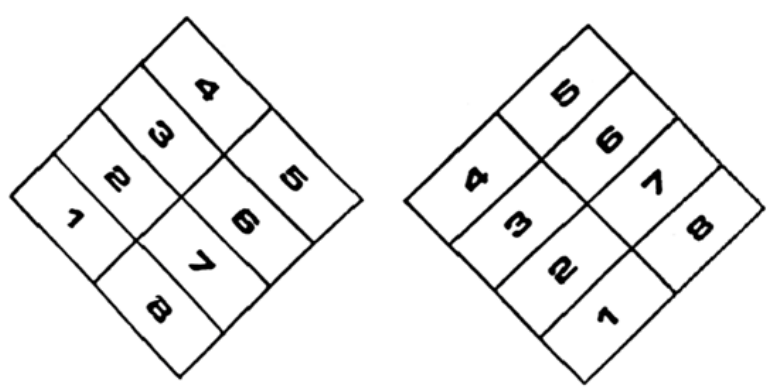

Fig. 4. Compaction of mortar specimen for compressive strength in one specimen. 




Fig. 5. Compressive strength test of mortar.

$$
\text { Compressive strength }=\frac{P}{A} \mathrm{~N} / \mathrm{mm}^{2}
$$

where $\mathrm{P}$ is the maximum load in $\mathrm{N}$ and $\mathrm{A}$ is the area of the surface loaded by the maximum load in $\mathrm{mm}^{2}$.

\section{Results and discussion}

\subsection{Fineness of cement}

The fineness of the cement is shown in Figure 6. The fineness of cement made with rice husk as a substitute fuel has a finer value than that required by SNI 20492015. The average value of the fineness of the cement is $380 \mathrm{~m}^{2} / \mathrm{kg}$, whereas the SNI requires $280 \mathrm{~m}^{2} / \mathrm{kg}$. The result is match to the SNI. If the gradation of the cement formed is very fine or finer than $380 \mathrm{~m}^{2} / \mathrm{kg}$, it takes more energy and fuel to drive the cement mill. A cement mill is a cylindrical piece of equipment in which thousands of steel balls are contained. As the cement mill spins, these steel balls clash together and crush the cement material fed into the mill, reducing the diameter of the cement particles. To rotate and move the cement mill to obtain finer cement gradation requires more energy, and the additional rotation of the cement mill increases the cost of cement production.

The rate of hydration and strength growth as well as the head released by the hydration process of the cement are significantly affected by the fineness of the cement. Drying shrinkage and cracks in the concrete structure will be generated by cement with a finer grain, and the cost to produce the finer cement will increase due to the consumption of fuel needed to grind the clinker. As another consequence of the finer grain of cement, more water for hydration is needed, and finally, the compressive strength and durability of the concrete will be decreased. Consumption of gypsum in cement manufacture, workability of the fresh concrete, and the long-term behavior of the hardened concrete are also influenced by the fineness of the cement.

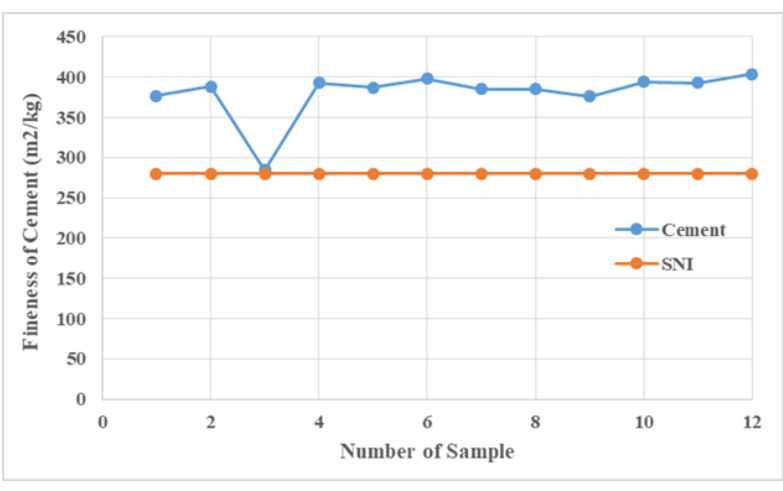

Fig. 6. Fineness of cement.

\subsection{False set}

Figure 7 shows the results of the false set test of cement produced with rice husk as a substitute for coal fuel. SNI 2049-2015 requires a $50 \%$ false set value. This requirement is given to avoid the apparent stiffening of the cement. The results of the false set test for cement produced with a portion of fuel in the form of rice husks gave an average false set of $81 \%$. This value is greater than that required by SNI 2049-2015, so the cement meets the standard value for the false set.

However, a high false set value has a negative effect on the concrete. False set is caused by alkali carbonate bound in the cement. False set can be avoided by protecting the cement from outside air influences so that alkali carbonate does not form inside the cement.

False set is a hydration reaction that occurs prematurely. This happens within minutes after the cement reacts with water and is due to the excessive amount of gypsum. If stirred again without adding water, its plasticity power will return, and the loss of final strength will not happen. As flash sets occurs due to the heat effect of the $\mathrm{C}_{3} \mathrm{~A}$ reaction with water, resulting from a high $\mathrm{C}_{3} \mathrm{~A}$ or gypsum content in the cement.

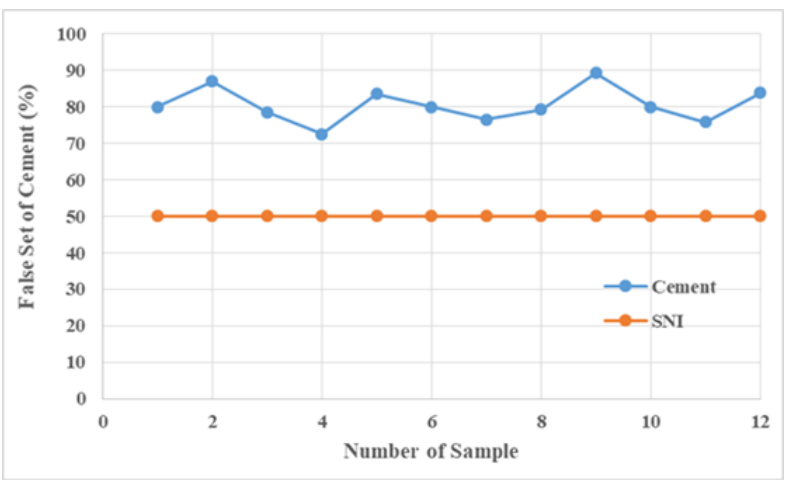

Fig. 7. False set of cement.

\subsection{Initial and final setting time}

The initial and final setting time of the cement can be seen in Figure 8. According to SNI 2049-2015, the initial and final setting time of Portland cement is set at a minimum of 45 minutes and maximum of 375 minutes. The results of our tests for the average initial and final 
setting times are 132 minutes and 253 minutes. Thus, the cement produced with some fuel in the form of rice husk had initial and final setting times that meet the SNI 2049-2015 standards.

The setting time of cement is very important because it affects the duration of the plasticity of the concrete. The faster the initial setting time, the shorter the workability time of the concrete. However, when the final setting time is too long, the concrete will take longer for the hardening process. This will affect the time of dismantling the form work that supports the concrete structure.

Initial and final cement setting times are strongly influenced by the content of $\mathrm{C}_{3} \mathrm{~S}, \mathrm{C}_{2} \mathrm{~S}, \mathrm{C}_{3} \mathrm{~A}$, and $\mathrm{C}_{4} \mathrm{AF}$. When the cement meets with water, the cement in the outer position will react first while the cement in the inner position will be gradually hydrated.

The fastest mechanism of setting when mixing with water is from the reaction between water and $\mathrm{C}_{3} \mathrm{~A}$ to form the compound $3 \mathrm{CaO} \cdot \mathrm{Al}_{2} \mathrm{O}_{3} \cdot 3 \mathrm{H}_{2} \mathrm{O}$ which is rigid and gel-shaped. The result of this reaction is the formation of an ettringite layer that encloses the surface of the compound. The occurrence of the osmosis process causes the ettringite layer to break, and the $\mathrm{C}_{3} \mathrm{~A}$ hydration reaction reoccurs. This process continues over and over until the gypsum content in the cement runs out. The osmosis process results in a stagnant hydration reaction.

The hydration reaction that occurs after several hours of water meeting with cement is the reaction of $\mathrm{C}_{3} \mathrm{~S}$ with water. This reaction produces calcium silicate hydrate (CSH). $\mathrm{CSH}$ will fill the cavities and form contact points so as to produce stiffness. At a later stage there is binding of CSH which will inhibit the mobility of the cement particles. So, finally, when the concrete becomes stiff and final setting is reached, then the process of hardening begins.

The speed of the hydration reaction reaches a maximum at an early stage and then decreases with time. This is due to the increasing number of CSH molecules on the cement crystals. The thicker the CSH layer, the slower the hydration. Theoretically, the hydration process will stop when the layer thickness reaches 25 microns. Portland cement generally has a crystal size between 5 to 50 microns. The cement hydration process requires as much as $20 \%$ water by weight of cement (water/cement factor $\mathrm{w} / \mathrm{c}=0.2$ ).

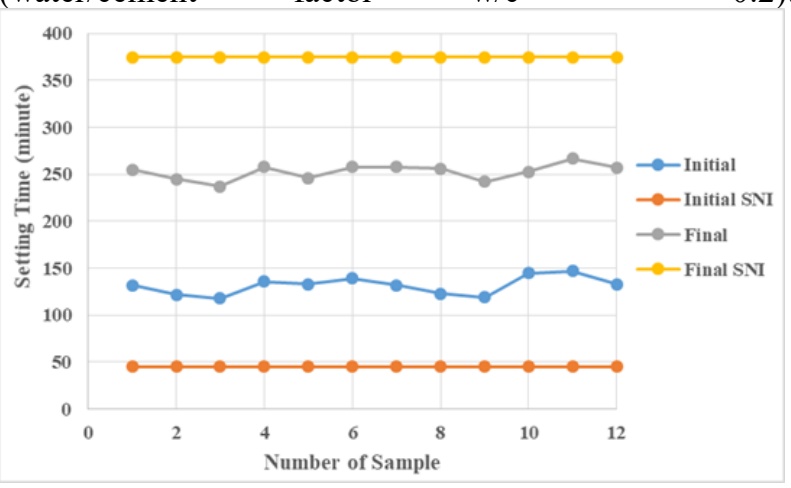

Fig. 8. Initial and final setting time of cement.

\subsection{Compressive strength of mortar}

The compressive strength of the mortar aged 3, 7, and 28 days is shown in Figure 8. The compressive strength of mortar required by SNI 2049-2015 is 135,215 , and 300 $\mathrm{kg} / \mathrm{cm}^{2}$ at an age of 3,7 , and 28 consecutive days. Based on Figure 9, the average compressive strength of our mortar at 3,7 , and 28 days is 225,298 , and $379 \mathrm{~kg} / \mathrm{cm}^{2}$, respectively. This shows that the mortar compressive strength using cement produced with rice husk as a substitute fuel for coal meets the requirements set in SNI 2049-2015.

Mortar compressive strength is strongly influenced by the content of $\mathrm{C}_{3} \mathrm{~S}, \mathrm{C}_{2} \mathrm{~S}, \mathrm{C}_{3} \mathrm{~A}$, and $\mathrm{C}_{4} \mathrm{AF}$ present in the cement. These compounds begin to react when mixed with water. The result of the hydration reactions between cement and water is the production of $\mathrm{CSH}$. The fastest reaction in producing $\mathrm{CSH}$ is the reaction between $\mathrm{C}_{3} \mathrm{~A}$ and water. The next hydration process is the reaction between $\mathrm{C}_{3} \mathrm{~S}$ and water, and then afterward is the reaction between $\mathrm{C}_{4} \mathrm{AF}$ and water. The slowest hydration reaction rate is for the hydration reaction between $C_{2} S$ and water. The reaction processes of these compounds affect the compressive strength of mortar at ages of 3, 7, and 28 days.

The strength of concrete at an early age is strongly influenced by the $\mathrm{C}_{3} \mathrm{~S}$ content whereas $\mathrm{C}_{2} \mathrm{~S}$ produces compressive strength of concrete over a long period of time. Furthermore, $\mathrm{C}_{3} \mathrm{~A}$ only affects the compressive strength of concrete up to the age of 28 days. After 28 days have elapsed, the effect of $\mathrm{C}_{3} \mathrm{~A}$ and $\mathrm{C}_{4} \mathrm{AF}$ on the concrete compressive strength decreases.

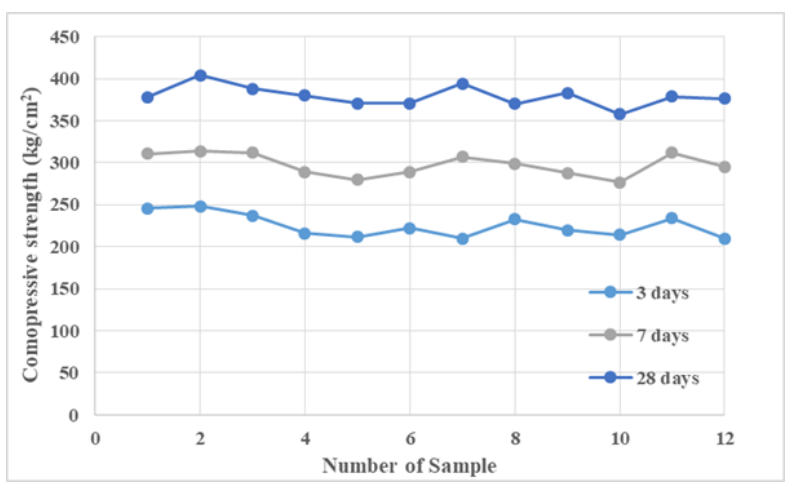

Fig. 9. Compressive strength of mortar. 


\section{Conclusions}

The effect of rice husk utilization as a substitute fuel for coal on the properties of the cement produced has been investigated. The physical properties of the cement including its fineness, false set, initial setting time, final setting time, and compressive strength of mortar at an age of 3, 7, and 28 days all meet the SNI 2049-2015 standard. Some conclusions can be given as follows:

- Fineness of the cement is $380 \mathrm{~m}^{2} / \mathrm{kg}$. This value is finer than the SNI standard of $280 \mathrm{~m}^{2} / \mathrm{kg}$.

- False set of the cement is $81 \%$, whereas SNI 2049-2015 requires a minimum of 50\%.

- Initial and final setting times of the cement are 132 minutes and 253 minutes, respectively. SNI 2049-2035 requires initial and final setting times with a minimum of 45 minutes and a maximum of 375 minutes consecutively.

- Compressive strength of mortar at 3, 7, and 28 days is 225,298 , and $379 \mathrm{~kg} / \mathrm{cm}^{2}$, respectively; the SNI standard states that the compressive strength of mortar should be 135, 215, and 300 $\mathrm{kg} / \mathrm{cm}^{2}$ at 3,7 , and 28 days, respectively.

Great appreciation is conveyed to Mrs. Ir. Ning Nastiti, Head of the Physics Laboratory of PT. Holcim Indonesia, Plant Cilacap, and also to Doni, Ratri, and Tika, EVE (Enterprise Based Vocational Education) students who have given us the opportunity to retrieve and analyze this research data. Without their help, this research would not be able to be completed on time.

\section{References}

1. A. Maryoto, G.H. Sudibyo, $4^{\text {th }}$ ICRMC, Sebelas Maret University (2018).

2. G.L. Oyekan, O.M. Kamiyo, $32^{\text {nd }}$ Conference on Our World in Concrete 7 Structure (2007).

3. J. Hadipramana, A.A.A. Samad, A.M.A. Zaidi, N. Mohammad, F.V Riza, Adv. Mat. Res. 626 (2013).

4. N.K. Krishna, S. Sandeep, K.M. Mini, IOP Conf. Mat. Sci. Eng. 149 (2016)

5. B.I. Rasoul, F.K. Gunzel, M.I. Rafiq, Mech. Mat. Sce. Eng. Septermber (2017)

6. A.B. Srinivasreddy, T.J. McCarthy, E. Lume, Con. Inst. of Australia's Conf. (2013)

7. C.B. Sisman, E. Gezer, I. Kocaman, Bulgarian J. Agri. Sci. 17, (2011)

8. M.U. Dubai, C. Muhammad, B.U. Bagudo. A. Musa, Nigeria J. Bsc. App. Sci. 17, 2 (2009).

9. A.M. Pande, S.G. Makarande, Int. J. Eng. Res. App. 3, 1 (2013)

10. A.N. Swaminathen, S.R. Ravi, Int. J. App. Eng. Res. 11, 1 (2016)

11. P. Singh, T. Sing, G. Sing, Indian J. Sci. Tech. 9, 47 (2016)

12. R.K. Sharma, J. Civ. Eng. 18, 7 (2014).

13. B.D. Reddy, S.A. Jyothy, L.V.R Reddy, Int. J. Civ. Struc. Env. Inf. Eng. 3, 1 (2013)

14. R.S. Deotale, S.H. Sathawane, A.R. Narde, Int. J. Sci. Eng. Res. 3, 6 (2012)

15. H.K. Venkatanarayanan, P.R. Rangaraju, Cem. Conc. Comp. 55 (2015)

16. Indonesia National Standard, SNI 2049-2015, BSN (2015). 